\title{
Can the consent provisions in the Choice on Termination of Pregnancy Act, which do not require children to be assisted by a parent or guardian, be used for live births by caesarian section in emergency situations?
}

\author{
D J McQuoid-Mason, BCom, LLB, LLM, PhD \\ Centre for Socio-Legal Studies, Howard College School of Law, University of KwaZulu-Natal, Durban, South Africa
}

Corresponding author: D J McQuoid-Mason (mcquoidm@ukzn.ac.za)

\begin{abstract}
The answer to the question as to whether in emergency situations, when there is no time for the procedures in the Children's Act No. 38 of 2005 to be followed, doctors may use the consent provisions in the Choice on Termination of Pregnancy Act No. 92 of 1996 (CTOP), which do not require children to be assisted by a parent or guardian, for live births by caesarian section, will depend on how'termination of pregnancy' is defined and interpreted in the CTOP. It is argued that, unless it is modified by Parliament or the courts, the definition in the Act is sufficiently wide to justify doctors using the provisions applicable to the third trimester to rely on the consent of the child alone, in situations where the caesarian section is performed to save the mother's life or to prevent the fetus suffering the risk of injury. Whatever Parliament or the courts decide, doctors can always fall back on the 'best interests of the child' Constitutional principle, using the provisions in the CTOP and standards in the Children's Act as guidelines for determining the pregnant child's 'best interests' in emergency situations requiring a caesarian section, where there is no time to obtain the consent required by the Children's Act. Such an approach is also consistent with the bioethical principles of patient autonomy, beneficence, non-maleficence and justice or fairness.
\end{abstract}

S Afr J Bioethics Law 2018;11(1):43-45. DOI:10.7196/SAJBL.2018.v11i1.644

Generally, in emergency situations, medical treatment and surgical operations may be undertaken without consent - provided they are not against the expressed wishes of the patient. ${ }^{[1]}$ In the case of children facing medical emergencies, special procedures are provided for in the Children's Act No. 38 of 2005..$^{[1]}$ The Act provides that the superintendent of a hospital, or the person in charge of the hospital in their absence, may consent to the medical treatment or surgical operation on a child if (i) the treatment or operation is necessary to preserve the life of the child or to save the child from serious lasting physical injury or disability, and (ii) the need for treatment or an operation is so urgent that it cannot be deferred for the purpose of obtaining the consent that would otherwise be required.Where an urgent caesarian section has to be performed on a pregnant child, and there is no time to comply with these provisions, some doctors have relied on the child's consent alone by applying the third trimester provisions of the Choice on Termination of Pregnancy Act No. 92 of 1996 (CTOP) ${ }^{[3]}$ (Dr Neil F Moran, personal communication).

In light of the above, the Head of Clinical Department: Obstetrics and Gynaecology, Department of Health, KwaZulu-Natal, has recently raised the question of whether the consent provisions in the CTOP may be used for live births by caesarian section on children in emergency situations (Dr Neil F Moran, personal communication). When interpreting a statute a judge will not simply rely on the grammatical meaning of the words in the text. The judge will consider them in the context of the Act, and try to interpret the Act in line with what they regard as the purpose of the legislation and in favour of the persons the Act seeks to protect, as demonstrated in the purpose of, or preamble to, a statute. ${ }^{[4]}$
To answer the question as to whether the consent provisions of the CTOP can also be used for live births, it is necessary to consider (i) the definition of 'termination of pregnancy' in the CTOP; (ii) the purpose of the CTOP; (iii) the definition of 'abortion' in the Abortion and Sterilization Act No. 2 of 1975 (Abortion Act), ${ }^{[5]}$ which the CTOP repealed because it was too restrictive; and (iv) whether the consent provisions in the CTOP may be used for live births by caesarian section on children. If the CTOP is used, the consent provisions in the Children's Act or any other law do not apply. ${ }^{[3]}$

\section{Meaning of 'termination of pregnancy' in the CTOP}

The ordinary dictionary meaning of 'termination' is to 'end' something, although the dictionary states that the secondary meaning of 'termination' in the context of 'termination of pregnancy' is 'an abortion, ${ }^{\prime[]}$ In order to determine the meaning intended by the CTOP, it is necessary to consider the definition provided in the Act. The Act defines 'termination of pregnancy' as 'the separation and expulsion, by medical or surgical means, of the contents of the uterus of a pregnant woman'.[3] This is a much wider definition than that used, for instance, in Rhode Island in the USA, which makes it clear that it refers to abortion by stating that 'termination of pregnancy ... shall mean administering to a woman any medicine, drug, substance, or thing whatever, or the employment upon her of any instrument or other means whatever, with intent to procure or induce the miscarriage of such woman' ${ }^{[7]}$ Zambia has a Termination of Pregnancy Act that does not define 'termination of pregnancy', but instead refers directly 
to 'abortion' throughout the Act. ${ }^{[8]}$ Zimbabwe also has a Termination of Pregnancy Act in which it is stated that the purpose is to 'change the law relating to abortion by defining the circumstances in which a pregnancy may be terminated.[9] The Act goes on to state that: 'Any reference in this Act to the termination of a pregnancy shall be construed as meaning the termination of a pregnancy otherwise than with the intention of delivering a live child. ${ }^{[9]}$

In the South African CTOP, the term 'contents of the uterus' clearly refers to the fetus. However, the Act begs the question as to whether a caesarian section that involves the removal of a live fetus from the mother's uterus, amounts to 'the separation and expulsion, by ... surgical means, of the contents of the uterus of a pregnant woman. ${ }^{[3]}$ The answer must be in the affirmative, because a caesarian section is a surgical procedure which separates and expels the fetus from its mother's uterus. A caesarian section that separates a live fetus from its mother's uterus satisfies the wide definition of 'termination of pregnancy' in the CTOP. As the CTOP allows terminations of pregnancy in the third trimester, where the fetus is viable, and the continued pregnancy will 'endanger the woman's life' or would 'pose a risk of injury to the fetus, ${ }^{[3]}$ it can be argued that such a caesarian section would be lawful if undertaken in terms of the Act. This is because if surgical terminations may be undertaken for abortions after the 20th week of gestation, there is no reason in principle why the provisions of the CTOP may not also be used for live births after the 20th week - in situations where the mother's life is endangered or there is a risk of injury to the fetus. Where they are applicable, the relevant parts of the Act could be interpreted to apply to both abortions and live births.

\section{Purpose of the CTOP}

The argument that the CTOP may also apply to live births when the termination is undertaken in the third trimester is also strengthened by the stated purpose of the Act in the Preamble. ${ }^{[3]}$ This is stated to be that Parliament recognises, inter alia, that 'women have the right of access to appropriate healthcare services to ensure safe pregnancy and childbirth! ${ }^{[3]}$ This statement seems to indicate that the Act is not only aimed at terminating pregnancies in the context of abortions, but also at ensuring that women have access to proper health services so that they can have safe pregnancies and childbirth. On this interpretation, a caesarian section that needs to be undertaken in emergency situations, to save the life of the mother or a fetus in situations where the child mother wishes to have the baby, clearly falls into the category of 'a safe pregnancy and childbirth'.

In addition, the Preamble states that the Act 'repeals the restrictive and inaccessible provisions of the Abortion and Sterilization Act ... and promotes reproductive rights and extends freedom of choice by affording every woman the right to choose whether to have an early, safe and legal termination according to her individual beliefs. ${ }^{[3]}$ Once again, where in an emergency situation a caesarian section has to be performed on a pregnant child mother, to save her life and comply with her wish to save her unborn child from injury, this can be construed as the mother exercising her 'right to have an early, safe and legal termination:

\section{Definition of 'abortion' in the Abortion Act}

The Abortion Act defined an 'abortion' as 'the abortion of a live fetus of a woman with intent to kill such fetus.[7] The emphasis on the killing of a fetus is consistent with the definition of terminations of pregnancy in Rhode Island, where reference is made to procuring or inducing miscarriages in pregnant women; ${ }^{[7]}$ in Zambia, where direct reference is made to abortions in their Termination of Pregnancy $\mathrm{Act}_{;}{ }^{[8]}$ and in Zimbabwe, where terminations of pregnancy are those that are undertaken 'otherwise than with the intention of delivering a live child! ${ }^{[9]}$

As previously mentioned, the CTOP is aimed at overcoming the 'restrictive' provisions of the Abortion Act - and it can be argued that the very narrow definition of abortion in the Abortion Act is one of the 'restrictive' provisions that the CTOP was designed to eliminate. There is no mention of 'procuring an abortion, ${ }^{\text {, } 8]}$ or 'to procure or induce a miscarriage ${ }^{[7]}$ or undertaking a procedure 'otherwise than with the intention of delivering a live child ${ }^{[9]}$ in the definition of 'termination of pregnancy' in the CTOP. The CTOP does not narrow the definition of termination of pregnancy, and in the context of the Act as a whole, there is no provision that indicates that the Act only applies to abortions. Some provisions may not be relevant to live births, such as those dealing with terminating pregnancies during the first and second trimesters when a fetus is not viable, but this does not mean that the provisions for the third trimester should only apply to abortions if they are broad enough to apply to live births.

\section{Can the consent provisions in the CTOP be used for live births by caesarian section on children?}

The CTOP states that a termination of pregnancy may only be undertaken with the consent of the pregnant person. In the case of children, they should be advised to consult with their parents, guardian, family members or friends before their pregnancy is terminated, but if they choose not to, the termination of pregnancy 'shall not be denied' ${ }^{[3]}$ Furthermore, the consent provisions in the CTOP apply 'notwithstanding any other law or the common law, ${ }^{\prime[3]}$ which means that the provisions of the Children's Act dealing with consent by children in the case of surgical procedures, where they require assistance from their parent or guardian, do not apply.

Although not yet decided by the courts, it is submitted that the wording in the CTOP can be interpreted to also apply to live births because (i) the definition of 'termination of pregnancy' in the Act is wide enough to apply to both abortions and live births in the third trimester, and (ii) the purpose of the Act is, inter alia, to ensure 'safe pregnancy and childbirth' and to allow women to choose to have 'an early, safe and legal termination. ${ }^{[3]} \mathrm{A}$ caesarian section is a surgical method of terminating a pregnancy as it expels and removes a fetus from its mother's uterus, as provided for in the Act. It can be argued, therefore, that in the third trimester, when the fetus is viable, a pregnant child may alone consent to a termination of pregnancy by caesarian section to deliver a live baby, in order to save her own life or to prevent the fetus from suffering the risk of injury, as provided for in the Act. If this interpretation is correct, then it would apply whether or not the doctors involved were faced with an emergency situation, as they would not be bound by the provisions of the Children's Act. ${ }^{[3]}$

It is submitted that the ordinary meaning of the words 'termination of pregnancy' as defined in the CTOP are broad enough to encompass terminations through caesarian section in the third trimester for the reasons set out above. Should the legislators wish the CTOP to apply only to abortions in the third trimester, they should limit 
the definition of terminations of pregnancy to those specifically undertaken to 'procure an abortion'; ; ${ }^{[8]}$ to 'kill a fetus'; ; ${ }^{[5]}$ to terminate a pregnancy 'otherwise than with the intention of delivering a live child'; $;{ }^{[10]}$ or to 'procure or induce a miscarriage. ${ }^{[7]}$ Until the courts or Parliament decide otherwise, it can be argued that doctors are fully justified in relying on the consent of the child alone in terms of the CTOP, when conducting caesarian sections for live births during the third trimester, where they are done to save the mother's life or to prevent the fetus from suffering a risk of injury.

Whatever Parliament or the courts decide, doctors can always fall back on the 'best interests of the child' principle in the Constitution, ${ }^{[10]}$ using the provisions in the CTOP and the standards mentioned in the Children's Act as guidelines for determining the pregnant child's 'best interests' in emergency situations where there is no time to obtain the consent required by the Children's Act. ${ }^{[11]}$ Such an approach is also consistent with bioethical principles of patient autonomy, beneficence, non-maleficence and justice or fairness. ${ }^{[12]}$

Acknowledgements. Dr Neil F Moran, Head of Clinical Department: Obstetrics and Gynaecology, KwaZulu-Natal Department of Health.

Author contributions. Sole author.

Funding. National Research Foundation.

Conflicts of interest. None.
1. McQuoid-Mason DJ. Medical Professions and Practice. The Law of South Africa. 2nd ed. Durban: LexisNexis, 2008: Vol 17 part 2: para 43.

2. South Africa. Children's Act No. 38 of 2005.

3. South Africa. Choice on Termination of Pregnancy Act No. 92 of 1996.

4. Du Plessis LM. Statute Law and Interpretation. The Law of South Africa. 2nd ed. Durban: LexisNexis, 2011, Vol 24 part 1: paras 323 and 361.

5. South Africa. Abortion and Sterilization Act No.18 of 1976.

6. Hornby AS. Oxford Advanced Dictionary of Current English. 3rd ed. Oxford: Oxford University Press, 1986.

7. State of Rhode Island and Providence Plantations Department of Health. Section 1.5 of the Rules and Regulations for the Termination of Pregnancy. R23-1-TOP. 1973. https://sos.ri.gov/documents/archives/regulations/released/pdf/ DOH/ DOH 32.pdf (accessed 18 April 2018).

8. Zambia. Section 2 of the Termination of Pregnancy Act 76 of 1972. Chapter 304. https://www.Zambia.org/zm/legislation/consolidated_act/304 (accessed 18 April 2018).

9. Zimbabwe. Preamble to the Termination of Pregnancy Act No. 29 of 1977. Chapter 15.10. www.parlzim.gov.zw/acts-list/termination-of-pregnancyact-15-10 (accessed 18 April 2018).

10. Constitution of the Republic of South Africa, 1996.

11. McQuoid-Mason D. Mandatory reporting of sexual abuse under the Sexual Offences Act and the 'best interests of the child'. S Afr J Bioethics Law 2011;4(2): 74-78.

12. Beauchamp TL, Childress JF. Principles of Biomedical Ethics. 3rd ed. Oxford: Oxford University Press, 1989.

Accepted 12 June 2018 